\title{
Characterization and adsorption properties of low-cost sewage sludge-derived carbon by using poly-aluminium chloride as pore-forming agent
}

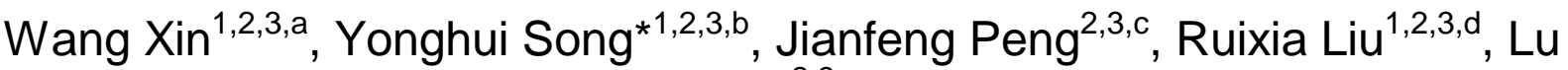 \\ $\mathrm{Han}^{2,3, \mathrm{e}}$
}

1. College of Water Science, Beijing Normal University, Xinjiekou Wai Street 19, Beijing 100875, PR China.

2. State Key Laboratory of Environmental Criteria and Risk Assessment, Chinese Research Academy of Environmental Sciences, Dayangfang 8, Anwai Beiyuan, Beijing 100012, PR China.
3. Department of Urban Water Environmental Research, Chinese Research Academy of Environmental Sciences, Dayangfang 8, Anwai Beiyuan, Beijing 100012, PR China.
axinwang-fly@163.com, bsongyh@craes.org.cn, cpjf1995@163.com, dliurx@craes.org.cn, 'hanlu@craes.org.cn

\begin{abstract}
Keywords: Sludge, Carbon, Poly-aluminium chloride, Pore-forming agent, Porous materials Abstract. We have demonstrated a facile and economical method for the synthesis of the sewage sludge-derived carbon. This product was prepared by using poly-aluminium chloride (PAC) as pore-forming agent through high-temperature pyrolysis at $900^{\circ} \mathrm{C}$, and employed for the removal of phenol from water. Thermodynamic properties, textural evolution, morphological structure, and surface functional groups of product are characterized. Moreover, the total pore volumes and SSA of the residual carbon increased to $0.1727 \mathrm{~cm}^{3} / \mathrm{g}$ and $141.2 \mathrm{~m}^{2} / \mathrm{g}$, that expanded to 2.3 times and 2.5 times compared with direct carbonized sample $\left(0.075 \mathrm{~cm}^{3} / \mathrm{g}\right.$ and $\left.55.45 \mathrm{~m}^{2} / \mathrm{g}\right)$, respectively. The results indicated that the addition of PAC had important effect on the texture, surface properties and adsorption performance. The adsorption kinetics and isotherms studies were investigated in details to reveal that the kinetics and equilibrium adsorptions are well-described by pseudo-second-order kinetics and Langmuir isotherm model, respectively. Remarkably, the resulting adsorbent showed comparably adsorption capacity with the commercial activated carbons. Meanwhile, our method is more economical than other chemical activation methods.
\end{abstract}

\section{Introduction}

Sewage sludge is the main by-product originating from sewage treatment plants. In the past years, the sewage sludge has dramatically increased due to the ever-increasing demand for water treatment and has resulted in severe environmental problems. Thus, disposal and resource use the sewage sludge have aroused wide attention. Over the last decades, great efforts have been focused on the preparation of effective and low-cost carbonaceous adsorbents from a wide range of waste materials, such as plant straw, agricultural wastes, sewage sludge, and other production residues [1-5].

Early in 1971, the first preliminary study on producing sewage sludge-derived adsorbents by chemical activation was carried out by Kemmer et al [6]. Subsequently, many scientific researches have been reported about the sewage sludge-derived adsorbents on a laboratory scale for environmental applications [7-10]. They have been proved to be excellent adsorbents for the removal of gaseous pollutants, metal cations, dyes and organic matters, etc [8, 10-13]. Generally, these carbonaceous materials can be produced by direct thermal pyrolysis, physical activation, or chemical activation under high carbonization temperatures. For example, Andrey Bagreev and Svetlana Bashkova reported that sewage sludge-derived adsorbents obtained at $950{ }^{\circ} \mathrm{C}$ has a capacity twice of that of coconut shell-based activated carbon for hydrogen sulfide. And the capacity of the sludge-derived carbons increases with increasing carbonization temperature [14]; Li et al. prepared sludge-derived activated carbon from paper mill sewage sludge at low temperature followed by physical activation with steam. 
The maximum adsorption capacity $(263.16 \mathrm{mg} / \mathrm{g}$ for Methylene Blue and $34.36 \mathrm{mg} / \mathrm{g}$ for Reactive Red 24), high regeneration efficiency and low cost suggested their potential for removing dyes from aqueous solutions [15]; Kong et al. prepared sewage sludge-derived hierarchical porous char by coupling citric acid with $\mathrm{ZnCl}_{2}$ in a new two-step pore-fabricating process [10]. However, the high ash contents, probably account for more than $50 \%$ of the total weight after carbonization. Zou et al. got purified sludge carbon with removal of inorganic fractions through acid washing. The obtained purified sludge-derived adsorbent with abundant oxygen-containing groups are favorable for organic contaminant removal from wastewater [16]. Besides, increasing the carbon content by adding carbon-rich materials such as corn stalk, leaf litter, and straw was found beneficial to the specific surface area and the capture capacity of the sludge-derived adsorbent $[17,18]$. Further development focuses on the catalytic activation method in which sewage sludge as carbon precursors are physically mixed with metal complex or metal salts before carbonization or activation [19-21]. Transition metals display a dramatic catalytic effect on the formation of mesopores during the carbonization process. Meanwhile, the resulting dispersive inorganic phase in carbons usually contributed to the specific adsorption to the model adsorbate via surface complexation, cation exchange or acid-base interactions.

However, up to now, the most common and efficient method to fabricate sewage sludge-derived carbon (SSC) mainly focused on the use of the chemical activators involving $\mathrm{ZnCl}_{2}, \mathrm{H}_{3} \mathrm{PO}_{4}$ and $\mathrm{KOH}$. While a high mass ratio of activating agent to precursor and inevitable equipment corrosion limit its practical application. Therefore, it is necessary to reduce the dosage of activating agent or explore some effective agent substitutes. Taking into account the surface properties and production cost, the objective of this study was to explore a convenient and relatively cheap way by using poly aluminium chloride (PAC) as pore-forming additive to replace previous activating agents during the high-temperature carbonization. The characteristics such as morphological structure, textural properties and surface functional groups were determined. In addition, the effects of PAC concertration and sludge dosage on the texture were evaluated. Moreover, the adsorption kinetics and isotherms of phenol were analysed in details. Meanwhile, the superiority in capture ability and agent cost of prepared adsorbents were also investigated.

\section{Material and methods}

Materials

Taking dewatered excess sewage sludge from urban wastewater treatment plant as starting material, the SSC was prepared. The dewatered municipal sewage sludge was achieved by drying in air at $105 \square$ overnight as starting material, grounded in less than $0.15 \mathrm{~mm}$ for further utilization. The basic properties and main components in the ash of the used sludge are shown in Table 1 and Table 2. PAC $(\geq 88 \%)$, phenol, methylene blue (MB), berberine (BE) and bisphenol A (BPA) were purchased from Fuchen Chemical Reagent Co., Tianjin, China. All the reagents were analytical grade and directly used without any purification. Deionized water was used through the whole experiments.

Table 1. The proximate analysis and basic element distribution of the used sludge.

\begin{tabular}{llllllllll}
\hline \multirow{2}{*}{ Sample } & \multicolumn{3}{l}{ Proximate analysis (wt \%) } & \multicolumn{7}{l}{ Elemental analysis (wt \%) } \\
\cline { 2 - 10 } & $\mathrm{M}(\%)$ & $\mathrm{A}(\%)$ & $\mathrm{V}(\%)$ & $\mathrm{F}(\%)$ & $\mathrm{H}$ & $\mathrm{S}$ & $\mathrm{N}$ & $\mathrm{C}$ & $\mathrm{O}^{*}$ \\
\hline SS & 6.83 & 37.96 & 53.66 & 1.55 & 6.35 & 1.79 & 4.31 & 33.72 & 15.87 \\
\hline
\end{tabular}

M: moisture content, A: ash content, V: volatile content, F: fixed carbon content, $\mathrm{O}^{*}$ : difference method. 
Table 2. The main component in the ash of the used sludge.

\begin{tabular}{cl}
\hline $\begin{array}{c}\text { Main } \\
\text { component }\end{array}$ & $\begin{array}{l}\text { The content } \\
\text { (wt \%) }\end{array}$ \\
\hline $\mathrm{SiO}_{2}$ & 10.47 \\
$\mathrm{P}_{2} \mathrm{O}_{5}$ & 7.28 \\
$\mathrm{Al}_{2} \mathrm{O}_{3}$ & 5.96 \\
$\mathrm{CaO}$ & 4.06 \\
$\mathrm{Fe}_{2} \mathrm{O}_{3}$ & 2.69 \\
$\mathrm{MgO}$ & 1.81 \\
$\mathrm{~K}_{2} \mathrm{O}$ & 1.51 \\
$\mathrm{~S}$ & 1.14 \\
$\mathrm{Na}_{2} \mathrm{O}$ & 0.374 \\
$\mathrm{TiO}_{2}$ & 0.294 \\
$\mathrm{ZnO}$ & 0.124 \\
$\mathrm{Cl}$ & 0.109 \\
\hline
\end{tabular}

Synthesis of SSC

The SSC was prepared by using municipal sewage sludge, PAC as carbon precursor and pore-forming agent, respectively. Typically, $2.5 \mathrm{~g}$ of PAC was dissolved in $50 \mathrm{~mL} \mathrm{H}_{2} \mathrm{O}$ in a three-necked glass reactor at room temperature. Under stirring, $7.0 \mathrm{~g}$ of dried sludge was added into the flocculant mixture that was equipped with a mechanical stirrer, and the reaction mixture was stirred until the emulsified sludge appeared. Then the resultant mixture was dried at $60 \square$ overnight. After drying, the as-made sludge-flocculant mixture was then transferred to a tubular furnace under nitrogen flow at a heating rate of $15 \square / \mathrm{min}$, keeping the temperature at $900 \square$ for $1.0 \mathrm{~h}$. Then the product was ground and sieved to obtain powders with a diameter below $0.5 \mathrm{~mm}$. The as-made dried sludge-flocculant micelle and pristine sludge were denominated as PAC-SS and SS, respectively. The final products from different substrate conditions were denoted as SSC-P-x, where $\mathrm{x}$ stands for the concentration of PAC (\%) or the dosage of additive sludge (g), respectively. Besides, the optimum sample was denoted as SSC-P. The reference sample from direct carbonization without the addition of PAC was named as SSC. For comparison, the commercial activated carbons (AC-1, AC-2 and AC-3) were also employed as reference.

Material characterization

Nitrogen adsorption isotherms were measured by using $\mathrm{N}_{2}$-adsorption in a Tristar II 3020 (Micromeritics, USA). The morphology of the MACs was examined by scanning electron microscopy (SEM, SU-8010, Hitachi, Japan). Thermogravimetric analysis (TG/DSC, METTLER TOLEDO, Switzerland) of sludge was performed in a temperature range of ambient to $1000 \square$ in the presence of argon at the heating rate of $15^{\circ} \mathrm{C} / \mathrm{min}$, to determine the mass loss $(\%)$. The functional groups of samples were recorded by FT-IR analysis (Horiba, Bruker, Germany). The FT-IR spectra were recorded in the 4000 to $400 \mathrm{~cm}^{-1}$ range, and were collected after 256 scans at $4 \mathrm{~cm}^{-1}$ resolution. The elements composition, carbon $(\mathrm{C})$, nitrogen $(\mathrm{N})$, hydrogen $(\mathrm{H})$ and sulphur $(\mathrm{S})$ content, of the sludge were determined by elemental analyzer (Costech ECS4024, Element analysis system , Italy). The chemical composition of the waste sludge was determined by X-ray fluorescence spectrometer (XRF-1800, Shimazduo, Japan). X-ray diffraction (XRD) patterns were collected with a Rigaku $\mathrm{D} / \mathrm{max}$-IIIB diffractometer using $\mathrm{CuK} \alpha$ at step scan $0.02^{\circ}$ from $5^{\circ}$ to $80^{\circ}$. The resulting powder diffraction patterns were analyzed according to the Joint Committee on Powder Diffraction Standard data. The accelerating voltage and the applied current were $40 \mathrm{kV}$ and $40 \mathrm{~mA}$, respectively.

Aqueous solution adsorption test

Phenol was adopted as model pollutant. Batch adsorption tests were carried out to determine the adsorption isotherm and the adsorption kinetic curves. The isothermal adsorption of phenol in aqueous 
solution on SSC-P was performed like this: $0.02 \mathrm{~g}$ of the adsorbent was added into $50 \mathrm{~mL}$ of phenol solutions of prepared initial concentrations under stirring in a shaker bath (150 rpm at $25 \pm 1.5 \square)$ for $24.0 \mathrm{~h}$. The amount of phenol adsorbed per unit mass of the adsorbent was evaluated by using the mass balance equation:

$$
\mathrm{Q}=\left(\mathrm{C}_{0}-\mathrm{C}_{\mathrm{e}}\right) \mathrm{V}_{\mathrm{s}} / 1000 \times \mathrm{m}
$$

where $\mathrm{Q}(\mathrm{mg} / \mathrm{g})$ is the amount adsorbed per gram of adsorbent, $\mathrm{C}_{0}$ and $\mathrm{C}_{\mathrm{e}}$ are the initial and equilibrium concentrations of adsorbate in solution $(\mathrm{mg} / \mathrm{L})$, respectively. $\mathrm{V}_{\mathrm{s}}$ is the initial solution volume $(\mathrm{mL}) . \mathrm{m}$ is the adsorbent mass ( $\mathrm{g}$ ). The $\mathrm{pH}$ was adjusted to $9.0 \pm 0.1$ by adding $0.1 \mathrm{~mol} / \mathrm{L} \mathrm{HCl}$ or $0.1 \mathrm{~mol} / \mathrm{L} \mathrm{NaOH}$ into the aqueous solutions. All the experiments were conducted in triplicate, and the results were calculated as the mean values.

The commonly isotherm models, namely Langmuir and Freundlich were used to describe the adsorption of phenol onto SSC-P. The Langmuir isotherm indicates monolayer adsorption onto a completely homogeneous surface, and is given as

$$
q_{e}=\frac{Q \cdot b \cdot C_{e}}{1+b \cdot C_{e}}
$$

where $\mathrm{Q}(\mathrm{mg} / \mathrm{g})$ is the maximum uptake per unit mass of adsorbent to form a complete monolayer on the surface of adsorbent, and $b(\mathrm{~L} / \mathrm{mg})$ is a constant related to the affinity of the binding sites.

The empirical Freundlich isotherm based on sorption on a heterogeneous surface is given by

$$
q_{e}=K_{F} \cdot C_{e}^{\frac{1}{n}}
$$

where $K_{F}$ and $1 / n$ are the Freundlich constants which are indicators of the maximum adsorption capacity and intensity, respectively.

For phenol kinetic experiment, briefly, $250 \mathrm{ml}$ phenol solution of different initial concentrations $(25 \mathrm{mg} / \mathrm{L}, 50 \mathrm{mg} / \mathrm{L}, 75 \mathrm{mg} / \mathrm{L})$ and $0.25 \mathrm{~g} \mathrm{SSC}-\mathrm{P}$ was placed in a $500 \mathrm{~mL}$ conical flask. The initial $\mathrm{pH}$ of the solution was adjusted to $9.0 \pm 0.1$ with $0.1 \mathrm{M} \mathrm{NaOH}$ and $\mathrm{HCl}$ solution. All the conical flasks were agitated in shaker at $25 \pm 1^{\circ} \mathrm{C}$ and a rate of $150 \mathrm{rpm}$. One milliliter of sample was taken at 10, 20, 30, 40, 60, 80, 100, 120 and $180 \mathrm{~min}$ for analysis of phenol concentration. All the experiments were conducted in triplicate, and the results were calculated as the mean values. The kinetics studies were performed by measuring the residual concentration of phenol at preset time intervals. The kinetics data was usually evaluated by using two kinetics models, namely pseudo-first-order and Ho's pseudo-second-order models. Pseudo-first-order model is given by

$$
q_{t}=q_{e}\left(1-e^{-k_{1} t}\right)
$$

where $\mathrm{q}_{\mathrm{t}}(\mathrm{mg} / \mathrm{g})$ is the amounts of phenol adsorbed at time $\mathrm{t}(\mathrm{min})$, and $\mathrm{k}_{1}\left(\mathrm{~min}^{-1}\right)$ is the rate constant of first-order adsorption. The applicability of pseudo-first-order model indicates that the external diffusion is a significant step. Ho's pseudo-second-order equation based on chemical related adsorption is expressed as

$$
q_{t}=\frac{k_{2} q_{e}{ }^{2} t}{1+k_{2} q_{e} t}
$$

where $\mathrm{k}_{2}(\mathrm{~g} / \mathrm{mg} \mathrm{min})$ is the rate constant of pseudo-second-order adsorption.

Further comparative adsorption study was carried out by employing methylene blue (MB), berberine (BE) and bisphenol A (BPA) as model pollutants. SSC-P, SSC and three types of commercial activated carbons (AC-1, AC-2 and AC-3) were choosed as adsorbents. Batch adsorption was operated as above.

Analytical methods

All the pollutant samples were filtered using $0.22 \mu \mathrm{m}$ membrane filters. After that, the phenol concentrations in the supernatants was measured by using a high performance liquid chromatograph (Agilent 1260, USA). An Agilent Eclipse Plus C18 column $\left(4.6^{*} 250 \mathrm{~mm}, 5 \mu \mathrm{m}\right)$ was used for the separation. The mobile phase was the mixture of methanol and water $(60: 40, \mathrm{v} / \mathrm{v})$ at the flow rate of 1.0 $\mathrm{mL} / \mathrm{min}$. The detection wavelength was $280 \mathrm{~nm}$ and the injection volume was $10 \mu \mathrm{L}$. Under these 
conditions, the retention time for phenol was $7 \mathrm{~min}$. The MB, BE and BPA concentrations in the supernatants was measured by using an UV/vis spectrometer and calculated by the absorbance at 664 $\mathrm{nm}, 460 \mathrm{~nm}$ and $276 \mathrm{~nm}$, respectively.

\section{Results and discussion}

Thermal properties analyses

To veritably investigate the pyrolysis behaviors and clarify the role of PAC, the thermogravimetric (TG) and differential thermogravimetric (DTG) curves of the dried solids (SS, PAC, PAC-SS) are collected in Fig. 1. On the curves, various peaks related to the volatilization of organic compounds of sludge were detected. As shown in Fig. 1A, all samples showed obviously weight loss as the increased pyrolysis temperature, especially for SS and PAC. The dramatic mass loss about $61.46 \%$ and $45.65 \%$ for SS and PAC-SS, respectively, were observed during the pyrolysis process mainly due to the volatilization/decomposition of inorganic or organic substance. Meanwhile, the PAC lost its most mass about $56.38 \%$. In other words, through high-temperature pyrolysis, the spaces previously occupied by PAC in the mixture of PAC-SS was released due to its thermal decomposition. Fig. 1B shows the weight loss rate of SS and PAC-SS at temperatures between ambient and $1000{ }^{\circ} \mathrm{C}$ where the greatest part of devolatilization occurs at around $300^{\circ} \mathrm{C}$, which could correspond to the polymers present in the original sludge or generated during the pyrolysis process. As for the decomposition of SS and PAC-SS, the whole pyrolysis process can be divided into four stages: (1) First stage, the minor mass loss $<200^{\circ} \mathrm{C}$ could be attributed to the release of moisture or the removal of adsorbed water from the pores of the materials [21]; (2) Significant weight loss was observed between $200 \square$ and $500^{\circ} \mathrm{C}$, which could be attributed to the decomposition of the dead bacteria [22]; (3) The relative stabilization phase presented from $500 \square$ to $800 \square$, and no obviously mass loss was observed for all samples during this period; (4) With higher temperature, there was a marginal mass loss, which might be due to deep decomposition of some sludge components [23]. Compared with SS, it is worth noting that PAC-SS had weaker weightlessness peaks in the above four stages. Highlight, PAC-SS had delayed weight loss peak than pristine dry sludge as the increasing temperature that might be due to the relative better thermal stable of PAC. The relative thermal stable in high temperature is helpful to inhibit the shrinkage of carbon skeleton of the final product. As a result, plenty of additional pores caused by PAC volatilization were retained in residual carbons.
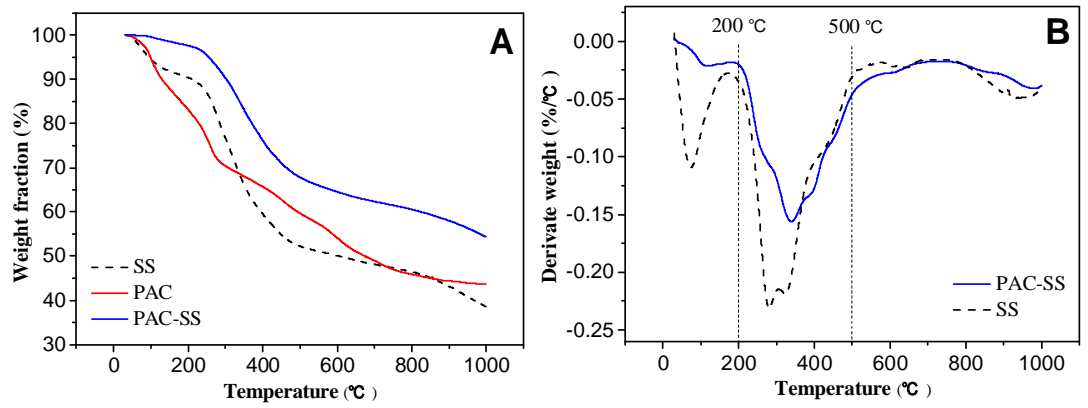

Fig. 1 TG and DTG analysis of the samples SS, PAC, SS-PAC performed in the temperature range of ambient to $1000^{\circ} \mathrm{C}$ with the presence of argon.

Textural properties analyses

Generally, the substrate conditions including carbon precursors and pore-forming agent have a great impact on the structure and pore size of materials [24]. So we investigate the effects of PAC concentration and sludge dosage on the structural feature. The $\mathrm{N}_{2}$ adsorption-desorption isotherms and pore size distributions curves for products obtained from different substrate conditions are shown 
in Fig. 2 and the corresponding textural parameters are summarized in Table 3. It can be seen that all isotherms (Fig. 2A and Fig. 2C) exhibit the same type-IV character nitrogen isotherm with hysteresis loops, which indicated that all samples had mesoporous structure. The presence of mesopores was also supported by the narrow pore size distribution concentrating in $3.6 \mathrm{~nm}$ and $3.8 \mathrm{~nm}$ as shown in Fig. $2 \mathrm{~B}$ and Fig. 2D.
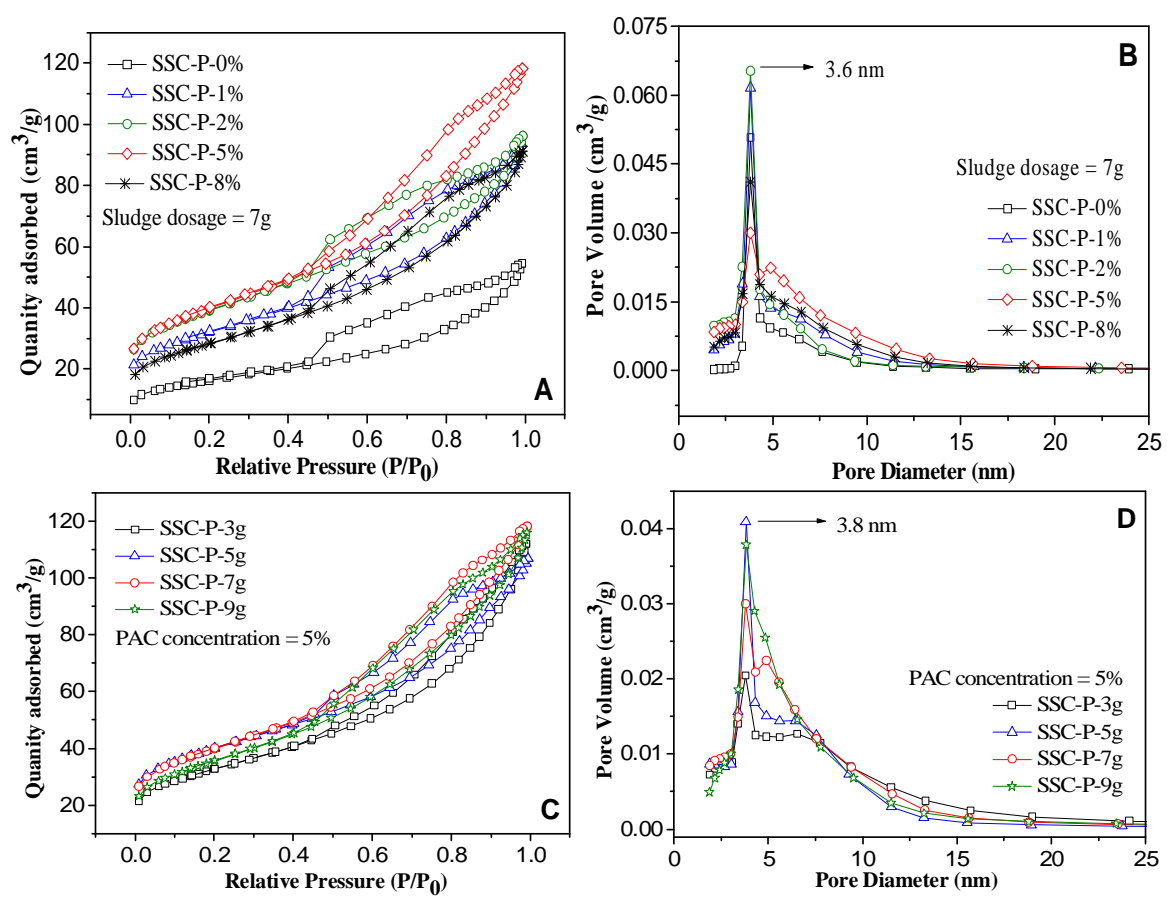

Fig. 2 A. $\mathrm{N}_{2}$ adsorption-desorption isotherm of samples prepared in different PAC concentrations; B. Resultant BJH pore size distribution of samples prepared in different PAC concentrations; C. $\mathrm{N}_{2}$ adsorption-desorption isotherm of samples prepared in different sludge dosages; D. Resultant BJH pore size distribution of samples prepared in different sludge dosages.

Compared with the bald one SSC-P-0\% $\left(55.45 \mathrm{~m}^{2} / \mathrm{g}\right)$, the addition of PAC enhanced the SSA obviously. While the increase of the SSA upon PAC was not mainly caused by the increase of micropore (Table 3). It means that the addition of PAC plays an inspiring effect in the forming of mesoporous or macropore, thus increasing the SSA. The increased PAC concentration provided a more developed porosity for achieving higher SSA and total pore volume. The same phenomenon can also be found as the increased sludge dosage. While these effects are limited, when the PAC concentration or sludge dosage reached a high level, such as $8 \%$ or $9 \mathrm{~g}$, the SSA and pore volume began to shrink. This can be explained as follow: with the increasing PAC concentration, the flocculant molecules forming much larger micelles diffused to sludge mixed liquor, which provided a range of pore network after pyrolysis, the higher concentration of PAC employed, the developed pore network can be built, while exorbitant PAC micelle might reduce total volatilization mass of per unit quantity since its better thermostability compared with sludge, thus resulting in the reduced trend of porous parameters. Moreover, incremental sludge offers more organic matter, which contains components and volatile matter that escape from the raw material at high temperature to form pore network. But a certain number of PAC concentration can only support a certain amount of carbon skeleton, redundant sludge would lead to the collapse of carbon skeleton. So the proper mass ratio of PAC to sludge is important for getting the optimized structure. Meanwhile, the highest SSA $\left(141.2 \mathrm{~m}^{2} / \mathrm{g}\right)$ and total pore volume $\left(0.1727 \mathrm{~m}^{2} / \mathrm{g}\right)$ were achieved when the sludge dosage was $7.0 \mathrm{~g}$ in the presence of $5 \%$ PAC. With regard to the average pore diameter $\left(D_{p}\right)$, the average aperture of the product increased from 3.95 $\mathrm{nm}$ to $5.19 \mathrm{~nm}$ with the aid of PAC. Nevertheless, the effect of additive sludge to average pore diameter was limited. 
Table 3. The parameters of the porous structure calculated from nitrogen adsorption isotherms for the samples obtained from different substrate conditions.

\begin{tabular}{cccccc}
\hline Sample & $\begin{array}{c}\mathrm{S}_{\mathrm{BET}} \\
\left(\mathrm{m}^{2} / \mathrm{g}\right)\end{array}$ & $\mathrm{S}_{\text {micro }}\left(\mathrm{m}^{2} / \mathrm{g}\right)$ & $\mathrm{D}_{\mathrm{p}}(\mathrm{nm})$ & $\mathrm{V}_{\text {total }}\left(\mathrm{cm}^{3} / \mathrm{g}\right)$ & $\mathrm{V}_{\text {micro }}\left(\mathrm{cm}^{3} / \mathrm{g}\right)$ \\
\hline $\begin{array}{c}\text { SSC-P-0 } \\
\%\end{array}$ & 55.45 & 8.27 & 3.95 & 0.075 & 0.003 \\
$\begin{array}{c}\text { SSC-P-1 } \\
\%\end{array}$ & 113.49 & 22.14 & 4.72 & 0.1338 & 0.00955 \\
$\begin{array}{c}\text { SSC-P-2 } \\
\%\end{array}$ & 138.2 & 32.56 & 4.00 & 0.1382 & 0.01429 \\
$\begin{array}{c}\text { SSC-P-5 } \\
\%\end{array}$ & 141.2 & 31.11 & 4.89 & 0.1727 & 0.01356 \\
SSC-P-8 & 99.87 & 10.94 & 5.19 & 0.1297 & 0.0043 \\
$\%$ & & & & & \\
$\begin{array}{l}\text { SSC-P-3g } \\
\text { SSC-P-5g }\end{array}$ & 116.07 & 23.66 & 5.47 & 0.1559 & 0.0102 \\
SSC-P-7g & 140.9 & 38.64 & 4.43 & 0.1587 & 0.0171 \\
SSC-P-9g & 126.38 & 31.11 & 4.89 & 0.1727 & 0.01356 \\
\hline
\end{tabular}

$\operatorname{BET} \operatorname{SSA}\left(\mathrm{S}_{\mathrm{BET}}\right)$, micropore $\mathrm{SSA}\left(\mathrm{S}_{\text {micro }}\right)$, average pore diameter $\left(\mathrm{D}_{\mathrm{p}}\right)$, total pore volume $\left(\mathrm{V}_{\text {total }}\right)$, and micropore volume $\left(\mathrm{V}_{\text {micro }}\right)$.

Crystalline phases (XRD) analyses

It can be seen from Fig. 3 that there is some macroscopic changes in the crystallinity degree and phases (crystal structures) after carbonization. It shows that the influence of carbonization or the addition of PAC on the microscopic lattice structure of products is available under inert atmosphere conditions. Quartz $\left(\mathrm{SiO}_{2}\right)$ is the main crystalline phases in all samples ( $\mathrm{SS}, \mathrm{SSC}$ and SSC-P). The broad intensity between 20 and 35 displays as a diffuse scattering and amorphous bulge between 20 and 35, which is attributed to the amorphous carbon. After high-temperature pyrolysis, some more plentiful crystalline phase emerged, such as lazurite, manganese nitride, calcium sulfate and calcium silicate, etc. While after the addition of PAC, a wide weak diffraction peaks ranging from 30 to 50 have shown in XRD spectra, which may correspond to the feature peaks of crystal planes of some minerals rich in aluminum, such as natrolite, wavellite, harmotome, etc. These results imply that after the introduction of PAC and carbonization, some new crystal phases containing calcium or aluminum have been successfully embedded in the carbons. Additionally, the residual impurities maybe the potential sites for some special bonding effects. 


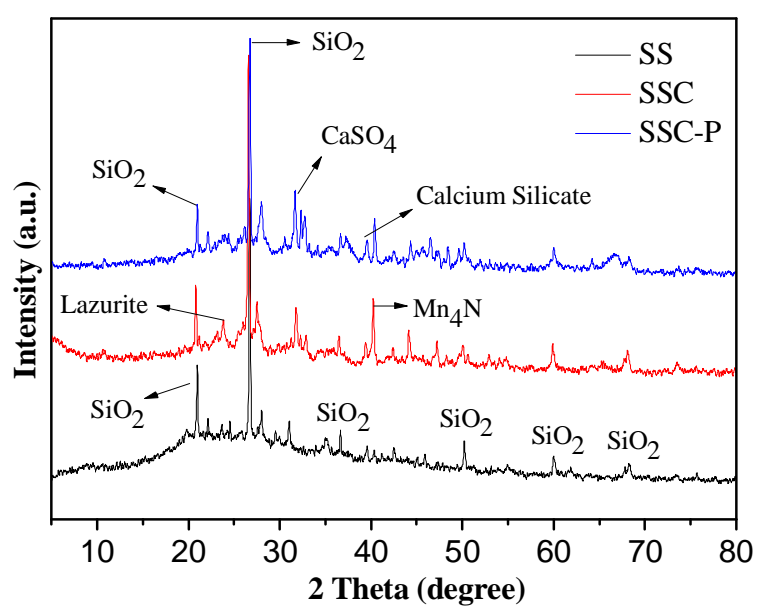

Fig. 3 XRD spectra of SS, SSC and SSC-P.

Functional groups analyses

The FTIR spectra of the samples (SS, SSC, SSC-P) are shown in Fig. 4. The bands at around 3420 $\mathrm{cm}^{-1}, 3390 \mathrm{~cm}^{-1}, 2920 \mathrm{~cm}^{-1}, 2850 \mathrm{~cm}^{-1}, 1654 \mathrm{~cm}^{-1}, 1550 \mathrm{~cm}^{-1}, 1403 \mathrm{~cm}^{-1}, 1035 \mathrm{~cm}^{-1}$ and $450 \mathrm{~cm}^{-1}$ are noticed for the pristine dry sludge. The wide peak at $3420 \mathrm{~cm}^{-1}$ correspond to the stretching vibration of the hydroxyl groups [25]. The intensity of this peak decreased after carbonization, indicating the ignition loss of $-\mathrm{OH}$ group because of the dehydration and the dehydrogenation reactions [26]. The bands at $3390 \mathrm{~cm}^{-1}$ could be attributed to the presence of $-\mathrm{NH}$ groups of protein, while the peaks around at $2920 \mathrm{~cm}^{-1}$ and $2850 \mathrm{~cm}^{-1}$ represented the asymmetric stretching vibration and symmetric stretching vibration of aliphatic functional group $-\mathrm{CH}_{2}$, respectively [27]. Thus the disappearance of above three peaks after carbonization suggested the thermal decomposition of the proteinic and aliphatic compounds. The peak at $1654 \mathrm{~cm}^{-1}$ implies the stretching vibration of $\mathrm{COO}, \mathrm{C}=\mathrm{O}$ and $\mathrm{C}-\mathrm{N}$ peptidic bond of proteins [28]. Its disappearance after carbonization could be attributed to the thermal decomposition of amides. In addition, the bands at $1550 \mathrm{~cm}^{-1}$ and $1403 \mathrm{~cm}^{-1}$ represent the $\mathrm{C}=\mathrm{O}$ stretching of carboxylate groups or carbonyl groups [29]. The band at $1035 \mathrm{~cm}^{-1}$ could be assigned to the alcohol groups. However, compared with the pristine sludge SS, the carbonized ones (SSC and SSC-P) have weaker intensity for above three bands $\left(1550 \mathrm{~cm}^{-1}, 1403 \mathrm{~cm}^{-1}, 1035 \mathrm{~cm}^{-1}\right)$, suggesting the reduction of oxygen-containing functional group after pyrolyzation. The band at $450 \mathrm{~cm}^{-1} \mathrm{can}$ be assigned to the Si-O-Si deformation. After carbonization, the bands between 800 and $450 \mathrm{~cm}^{-1}$ are quite different, which can be attributed to the difference between the bending modes of Si-O-Si (or $\mathrm{Si}-\mathrm{O}-\mathrm{X}, \mathrm{X}$ means $\mathrm{Al}, \mathrm{Fe}, \mathrm{Ca}, \mathrm{Mg}$, and $\mathrm{Na}$; or a combination of $\mathrm{Si}-\mathrm{O}-\mathrm{X}$ and $\mathrm{Si}-\mathrm{O}-\mathrm{Si}$ ) in SSC and SSC-P [16]. These complex components should be consist of tetrahedral silicate $\left(\mathrm{SiO}_{4}\right)$ with other inorganic components (such as $\mathrm{Al}, \mathrm{Fe}, \mathrm{Ca}, \mathrm{Mg}, \mathrm{Na}$, etc.). Nevertheless, these results are consistent with the corresponding phenomenon observed in XRD analysis.



Fig. 4 FTIR spectral for the samples SS, SSC and SSC-P.

Morphological structure analyses

Fig. 5 shows the structure of the products during different preparation processes. Pristine dry sludge imaging by SEM showed a series of loose and clastic morphologies as shown in Fig. 5A. After 
carbonization (Fig. 5B), the surface became smooth and structurally rigid, some apparent pits resulted from the evaporation of sludge containing organic compounds could also be found. With the addition of PAC, the precursors of sludge and PAC were mixed well due to the adsorption bridging effect, the flocculating bodies were constituted of PAC as framework covering with sewage sludge. Through high temperature calcination, the PAC started its pyrogenic volatilization and left the spaces previously occupied. These details have be clearly demonstrated by above pyrolytic and textural analysis. The surface feature of the optimized sample SSC-P with the existence of chasmal, irregular pores, and rough concave-convex surfaces were clearly observed (Fig. 5C). Besides, the results indicated that the holes inlaid in SSC-P were denser than the direct one SSC (Fig. 5B), which mainly due to the decomposed PAC and escaping of volatiles. Specially, some residual crystal block could be found in the channels of SSC-P (Fig. 5D).

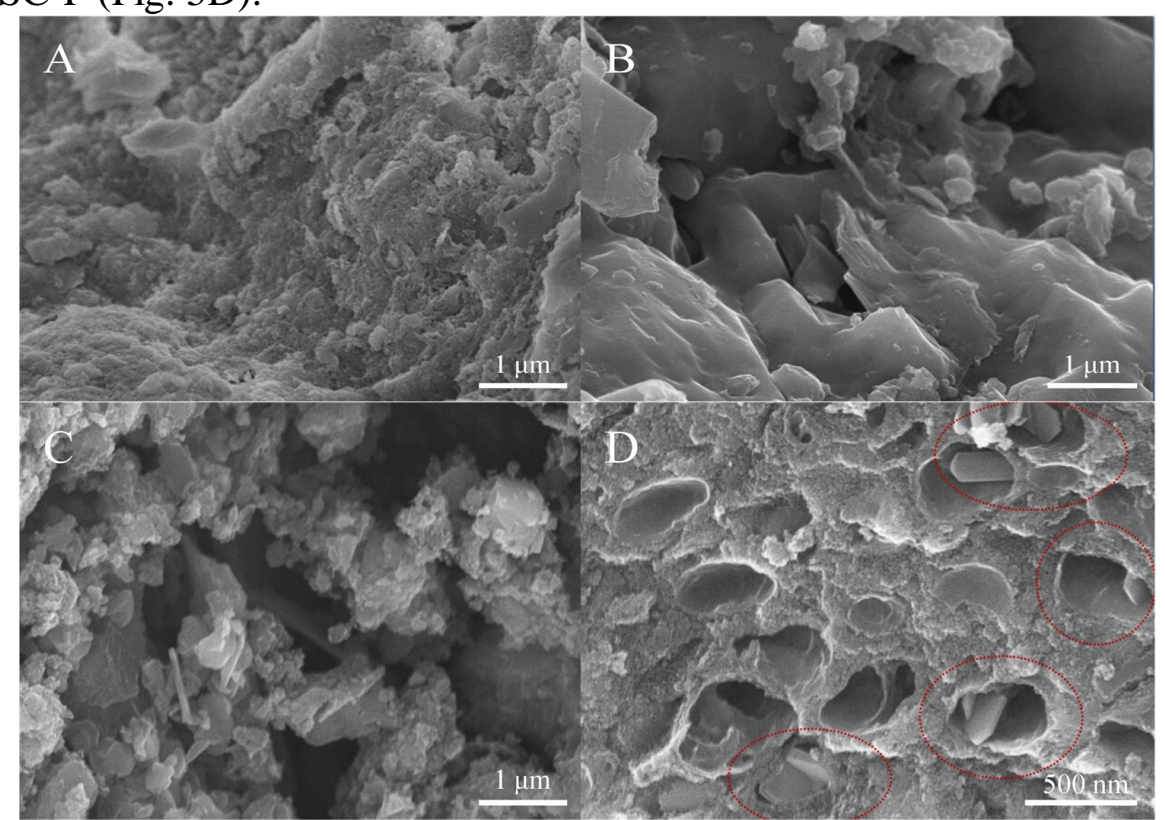

Fig. 5 SEM for (A). Pristine dry sludge; (B). Direct carbonized sample SSC; (C)(D). The optimized sample SSC-P. Preliminary adsorption studies

Adsorption isotherms of phenol by SSC-P are indicated in Fig. 6(A), and the isotherm constants for fitting Langmuir and Freundlich models are listed in Table 4. The results of Fig. 6(A) show a significant increase of the amounts of phenol adsorbed at equilibrium as temperature increases, while SSC-P achieved a maximum adsorption capacity of $127.75 \mathrm{mg} / \mathrm{g}$ at $313 \mathrm{~K}$. From the correlation coefficients (Table 4), it can be seen that Langmuir model provides the best fit in all cases, with very good values of the correlation coefficient, implying that the surface of SSC-P has the homogeneous binding sites and equivalent adsorption energies. Both the $\mathrm{K}_{\mathrm{L}}$ and $\mathrm{q}_{\mathrm{m}}$ values increased as the temperature increased, indicating the endothermic nature of phenol adsorption on SSC-P. Moreover, the $\mathrm{R}_{\mathrm{L}}$ values presented in Table 4 were all between 0 and 1, indicating that phenol onto the SSC-P was very favorable [30]. Whether Langmuir model or Freundlich model, it is interesting to observe the indicator of adsorption intensity, $\mathrm{K}_{\mathrm{L}}$ or $\mathrm{n}$, has the increasing order as the enhanced temperature, implying that the temperature could play an important role in intensifying the interaction between phenol and SSC-P. 

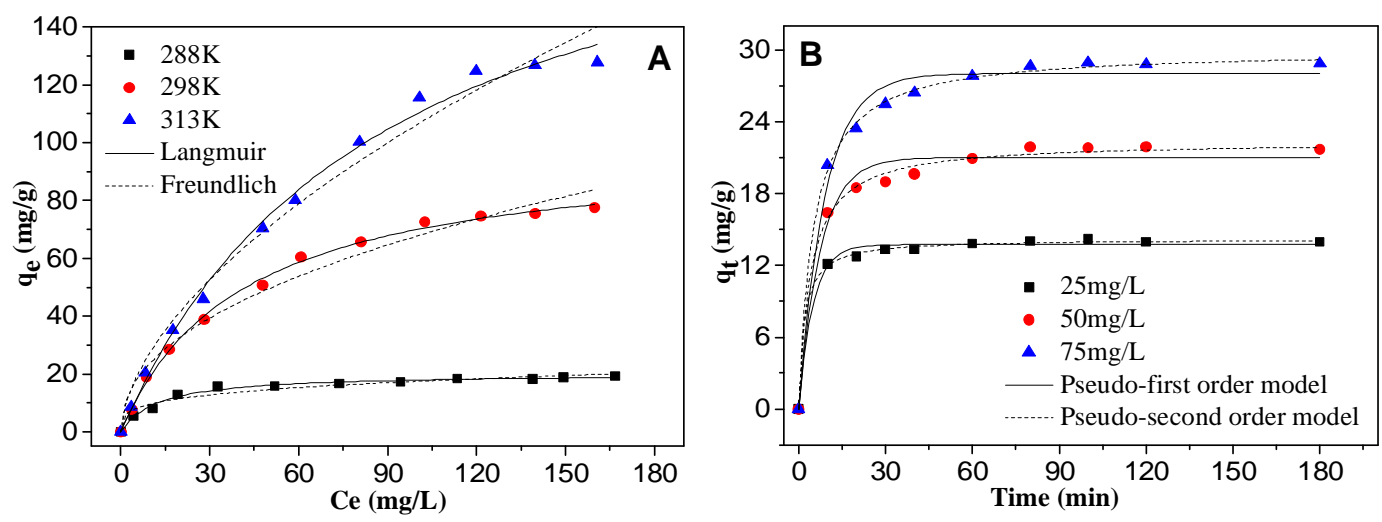

Fig. 6 (A) Adsorption isotherms of phenol on the optimum sample SSC-P at different temperatures and pH 9; (B) Adsorption kinetics of phenol on the optimum sample SSC-P at different initial concentrations and $\mathrm{pH} 9$ ( $\mathrm{T}=298 \mathrm{~K}$ ).

The influence of initial phenol concentration in the range of (25 to 75$) \mathrm{mg} / \mathrm{L}$ on phenol adsorption capacity of SSC-P was investigated and the results are shown in Fig. 6(B). The adsorption capacity increased with increasing concentration of phenol. This result may be due to that higher mass transfer driving force caused by concentration gradient between solution and adsorbent surface at high phenol concentration. Meanwhile, the adsorption reaches the adsorption equilibrium in less than an hour, and the adsorption equilibrium time is shorter when the concentration is lower. Table 5 summarizes the kinetic constants obtained by linear regression for the two models (Fig. 6(B)). For the pseudo-first-order model, the correlation coefficients $\left(\mathrm{R}^{2}\right)$ are relatively low, and the calculated $\mathrm{q}_{\mathrm{cal}}$ values do not agree with the experimental datas $\left(\mathrm{q}_{\text {mea }}\right)$ well, indicating that the phenol adsorption on the SSC-P cannot be explained by the pseudo-first-order model. In contrast, for the pseudo-second-order model, the $\mathrm{q}_{\mathrm{cal}}$ values agree very well with the experimental ones $\left(\mathrm{q}_{\mathrm{mea}}\right)$, showing a good linearity with $\mathrm{R}^{2}$ above 0.99 . Therefore, the adsorption kinetic follows the pseudo-second-order model.

Table 4 Langmuir and Freundlich model constants for SSC-P.

\begin{tabular}{cccccccc}
\hline \multirow{2}{*}{ Sample } & \multirow{2}{*}{ Temperature $(\mathrm{K})$} & \multicolumn{3}{c}{ Langmuir } & \multicolumn{3}{c}{ Freundlich } \\
\cline { 2 - 8 } & & $\mathrm{q}_{\mathrm{m}}(\mathrm{mg} / \mathrm{g})$ & $\mathrm{K}_{\mathrm{L}}(\mathrm{L} / \mathrm{mg})$ & $\mathrm{R}^{2}$ & $\mathrm{~K}_{\mathrm{F}}(\mathrm{mg} / \mathrm{g})$ & $\mathrm{n}$ & $\mathrm{R}^{2}$ \\
\hline SSC-P & 288 & 20.19 & 0.019 & 0.987 & 5.306 & 1.714 & 0.982 \\
SSC-P & 298 & 81.71 & 0.024 & 0.997 & 7.236 & 2.215 & 0.975 \\
SSC-P & 313 & 137.74 & 0.071 & 0.994 & 8.473 & 3.857 & 0.947 \\
\hline
\end{tabular}

Table 5 Pseudo-first order and Pseudo-second model constants for SSC-P.

\begin{tabular}{|c|c|c|c|c|c|c|c|c|}
\hline \multirow{2}{*}{ Sample } & \multirow{2}{*}{$\begin{array}{l}\text { Initial concentration } \\
\qquad(\mathrm{mg} / \mathrm{L})\end{array}$} & \multirow{2}{*}{$\begin{array}{c}\mathrm{q}_{\text {mea }} \\
(\mathrm{mg} / \mathrm{g})\end{array}$} & \multicolumn{3}{|c|}{$\begin{array}{l}\text { Pseudo-first order } \\
\text { model }\end{array}$} & \multicolumn{3}{|c|}{$\begin{array}{l}\text { Pseudo-second order } \\
\text { model }\end{array}$} \\
\hline & & & $\begin{array}{c}\mathrm{q}_{\mathrm{cal}} \\
(\mathrm{mg} / \mathrm{g})\end{array}$ & $\begin{array}{c}\mathrm{k}_{1} \\
\left(\min ^{-1}\right)\end{array}$ & $\mathrm{R}^{2}$ & $\begin{array}{c}\mathrm{q}_{\mathrm{cal}} \\
(\mathrm{mg} / \mathrm{g})\end{array}$ & $\begin{array}{c}\mathrm{k}_{2} \\
(\mathrm{~g} / \mathrm{mg} \min )\end{array}$ & $\mathrm{R}^{2}$ \\
\hline SSC-P & 25 & 14.21 & 13.73 & 0.201 & 0.991 & 14.20 & 0.0374 & 0.998 \\
\hline SSC-P & 50 & 21.92 & 21.02 & 0.132 & 0.975 & 22.25 & 0.0111 & 0.995 \\
\hline SSC-P & 75 & 29.92 & 28.03 & 0.109 & 0.982 & 30.01 & 0.0065 & 0.998 \\
\hline
\end{tabular}

$\mathrm{q}_{\text {mea }}$ : experimental maximum uptake; $\mathrm{q}_{\text {cal }}$ : calculated maximum uptake.

Potential superiority

To further comparative analysis the adsorption characters of the obtained SSC-P, SSC and three types of commercial activated carbons (AC-1, AC-2 and AC-3) were employed as reference. Moreover, $\mathrm{MB}, \mathrm{BE}$ and BPA were adopted as model pollutants. After adding $0.02 \mathrm{~g}$ five different kinds of adsorbents (SSC-P, SSC, AC-1, AC-2 and AC-3) to $50 \mathrm{~mL}$ above targets solution respectively, the solution was fully shocked for $24 \mathrm{~h}$ at ambient temperature. Then the adsorption capacities were investigated as presented in Fig. 7. The results show that the MB dye removal efficiency on all adsorbents were much better than BE and BPA, which might be associated with the water solubility of solutes. For above three model pollutants, the adsorption characters of the obtained SSC-P was roughly same as that of AC-3, and showed distinct advantages comparing with other carbons (SSC, $\mathrm{AC}-1$ and $\mathrm{AC}-2$ ). So it is proved that obtained SSC-P has a great potential to employ as environmental purification material. 




Fig. 7 Comparison of the maximum adsorption capacities of different adsorbates (MB, BE and BPA) onto various adsorbents.

Table 6 Comparison of agent cost calculation of different methods.

\begin{tabular}{ccccccc}
\hline $\begin{array}{c}\text { Chemical } \\
\text { agent } \\
\text { employed }\end{array}$ & $\begin{array}{c}\text { Sludge } \\
\text { dosage } \\
(\mathrm{g})\end{array}$ & $\begin{array}{c}\text { Agent } \\
\text { dosage } \\
(\mathrm{g})\end{array}$ & $\begin{array}{c}\text { Agent } \\
\text { dosage } \\
\text { used per } \\
\text { gram } \\
\text { sludge }(\mathrm{g} / \mathrm{g})\end{array}$ & $\begin{array}{c}\text { Agent price } \\
(\text { dollar/t })\end{array}$ & $\begin{array}{c}\text { Agent cost } \\
(\text { dollar/t })\end{array}$ & Ref. \\
\hline $\mathrm{ZnCl}_{2}$ & 40 & 272 & 6.8 & 890.66 & 6056.49 & {$[31]$} \\
$\mathrm{ZnCl}_{2}$ & 1 & 3 & 3 & 890.66 & 2671.98 & {$[32]$} \\
$\mathrm{ZnCl}_{2}$ & 40 & 68 & 1.7 & 890.66 & 1514.12 & {$[33]$} \\
$\mathrm{Citric} \mathrm{acid}$ & 40 & 48 & 1.2 & 504.71 & 605.65 & {$[33]$} \\
$\mathrm{H}_{2} \mathrm{SO}_{4}$ & 1 & 1.5 & 1.5 & 81.64 & 122.46 & {$[34]$} \\
$\mathrm{H}_{2} \mathrm{SO}_{4}$ & 1 & 1 & 1 & 81.64 & 81.64 & {$[35,36]$} \\
$\mathrm{KOH}$ & 20 & $20-80$ & $1-4$ & 371.11 & $371.11-1484.4$ & {$[37]$} \\
$\mathrm{PAC}$ & 7 & 2.5 & 0.357 & 207.82 & 74.19 & This \\
\end{tabular}

Usually, sewage sludge-based porous carbons were prepared by adding chemical activators under high temperature, such as $\mathrm{ZnCl}_{2}, \mathrm{H}_{2} \mathrm{SO}_{4}, \mathrm{KOH}$. In this section, the agent cost per ton of dried sludge was detailed calculation, including the mass of raw dried sludge used, agent dosage, and agent price (Table 6). Hereinto, the mass ratio of sludge to agent is different in each method, in this study, it was calculated as the agent dosage used per gram sludge. In our method, for producing $1 \mathrm{~g}$ SSC-P, the PAC consumption is $0.357 \mathrm{~g}$. So without considering the cost of drying, pyrolysis, depreciation, freight and labor input, the unit agent cost of our protocol is 74.19 dollar/t. The cost will further reduce in the process of large-scale production instead of laboratory scale. Meanwhile the agent cost $(74.19$ dollar/t) is the lowest one of the projects discussed in this study, so the sewage sludge-derived porous carbon based upon PAC is more economical.

\section{Conclusions}

In this work, we explore a new protocol for preparing sewage sludge-derived carbons by using PAC as pore-forming agent. This method not only provides a new technical proposal for the sludge 
resource usage, but also reduces the potential agent cost. The results show that PAC plays an important role in material texture and the adsorption capacity in the water solution. The SSA and pore volume all increased with the increasing PAC concentration and sludge dosage in a certain scope. The proper mass ratio of PAC to sludge is important for getting the optimized structure. The obtained optimum SSC-P could reach a high BET SSA of $141.2 \mathrm{~m}^{2} / \mathrm{g}$ and large pore volume of $0.1727 \mathrm{~cm}^{3} / \mathrm{g}$ when the PAC concentration was $5 \%$, sewage sludge dosage was $7 \mathrm{~g}$, and the pyrolysis temperature was $900^{\circ} \mathrm{C}$. The Langmuir model and pseudo-second-order kinetic model matched with the adsorption of phenol onto SSC-P well. Compared with commercial activated carbons, the product is comparably in the pollutants removal, and our method is more economical than the existing chemical activation technologies, indicating the great potential of this technology for sludge recycling and water treatment in the future applications.

\section{Acknowledgements}

This work was financially supported by National Major Program of Science and Technology for Water Pollution Control and Governance (Fund number, 2012ZX07202-005, PR China).

\section{References}

[1] X. Xu, Y. Kan, L. Zhao and X. Cao: Environmental Pollution Vol. 213 (2016), p. 533.

[2] A.E. Creamer, B. Gao and S. Wang: Chemical Engineering Journal Vol. 283 (2016), p. 826.

[3] X. Zhu, Y. Liu, Q. Feng, Z. Chao, S. Zhang and J. Chen: Bioresource Technology Vol. 154C (2014), p. 209.

[4] H. Li, R. Qu, L. Chao, W. Guo, X. Han, H. Fang, Y. Ma and B. Xing: Bioresource Technology Vol. 163 (2014), p. 193.

[5] R. Wallace, M. Seredych, P. Zhang and T.J. Bandosz: Chemical Engineering Journal Vol. 237 (2014), p. 88.

[6] R.S. Kemmer FN, Mattix RD, U.S. Patent 3,619,420. (1971)

[7] N.R. Khalili, M. Campbell, G. Sandi and J. Golaś: Carbon Vol. 38 (2000), p. 1905.

[8] Andrey Bagreev, D.C.L. and T.J.B.: Industrial \& Engineering Chemistry Research Vol. 40 (2001), p. 3502.

[9] F. Rozada, M. Otero, A. Morán and A.I. García: Journal of Hazardous Materials Vol. 124 (2005), p. 181.

[10] L. Kong, Y. Xiong, S. Tian, R. Luo, C. He and H. Huang: Bioresource Technology Vol. 146 (2013), p. 457.

[11] Y. Li, Y. Li, L. Li, X. Shi and Z. Wang: Advanced Powder Technology Vol. 27 (2016), p. 684.

[12] G. Tan, W. Sun, Y. Xu, H. Wang and N. Xu: Bioresource Technology Vol 211 (2016), p. 727.

[13] T. Chen, Z. Zhou, S. Xu, H. Wang and W. Lu: Bioresource Technology Vol 190 (2015), p. 388.

[14] Andrey Bagreev, Svetlana Bashkova, D.C.L. and T.J.B.: Environmental Science \& Technology Vol 35 (2001), p. 1537.

[15] W.H. Li, Q.Y. Yue, B.Y. Gao, Z.H. Ma, Y.J. Li and H.X. Zhao: Chemical Engineering Journal Vol 171 (2011), p. 320.

[16] J. Zou, D. Ying, W. Xue, Z. Ren, C. Tian, P. Kai, S. Li, M. Abuobeidah and H. Fu: Bioresource Technology Vol 142 (2013), p. 209.

[17] C. Wu, M. Song, B. Jin, Y. Wu and Y. Huang: Acta Scientiae Circumstantiae Vol 25 (2013), p. 405.

[18] X. Ren, B. Liang, M. Liu, X. Xu and M. Cui: Bioresource Technology Vol 125 (2012), p 300.

[19] L. Chen, Z. Tang, C. Yao, S. Su and W. Jiang: Bioresource Technology Vol 101 (2010), p 1097.

[20] L. Nielsen, P. Zhang and T.J. Bandosz: Chemical Engineering Journal Vol 267 (2015), p 170.

[21] G. Lin, N. Zhu, H. Guo, S. Huang, Z. Lou and H. Yuan: Journal of Hazardous Materials Vol 246-247C (2012), p 145. 
[22] R. Font, A. Fullana, J.A. Conesa and F. Llavador: Journal of Analytical \& Applied Pyrolysis Vol 58 (2001), p 927.

[23] J. Shao, R. Yan, H. Chen, B. Wang, H.L. Dong and D.T. Liang: Energy \& Fuels Vol 22 (2008), p 38.

[24] W. Xin, Y. Song: Rsc Advances Vol 5 (2015), p 83239.

[25] C. Peng, Y. Zhai, Z. Yun, B. Xu, T. Wang, C. Li and G. Zeng: Fuel Vol 176 (2016), p 110.

[26] P. Devi, A.K. Saroha: Bioresource Technology Vol 192 (2015), p 312.

[27] Y. Lin, D. Wang and T. Wang: Chemical Engineering Journal Vol 191 (2012), p 31.

[28] O. Gulnaz, A. Kaya and S. Dincer: Journal of Hazardous Materials Vol 134 (2006), p 190.

[29] C. Jindarom, V. Meeyoo, T. Rirksomboon and P. Rangsunvigit: Chemosphere Vol 67 (2007), p 1477.

[30] L. Ding, B. Zou, W. Gao, Q. Liu, Z. Wang, Y. Guo, X. Wang and Y. Liu: Colloids \& Surfaces A Physicochemical \& Engineering Aspects Vol 446 (2014), p 1.

[31] L. Kong, Y. Xiong, L. Sun, S. Tian, X. Xu, C. Zhao, R. Luo, X. Yang, K. Shih and H. Liu: Journal of Hazardous Materials Vol 274C (2014), p 205.

[32] F. Gorzin, A.A. Ghoreyshi: Korean Journal of Chemical Engineering Vol 30 (2013), p 1594.

[33] L. Kong, Y. Xiong, S. Tian, R. Luo, C. He and H. Huang: Bioresource Technology Vol 146 (2013), p 457.

[34] S. Rio, C. Faur-Brasquet, C.L. Le, P. Courcoux and C.P. Le: Chemosphere Vol 58 (2005), p 423. [35] M. Otero, F. Rozada, L.F. Calvo, A.I. GarciA and A. Morán: Dyes \& Pigments Vol 57 (2003), p 55.

[36] F. Rozada, L.F. Calvo, A.I. GarcíA, J. MartíN-Villacorta and M. Otero: Bioresource Technology Vol 87 (2003), p 221.

[37] H. Feng, M. Zheng, H. Dong, Y. Xiao, H. Hu, Z. Sun, C. Long, Y. Cai, X. Zhao and H. Zhang: Journal of Materials Chemistry A Vol 3 (2015), p 15225. 